\title{
An Inventory Model based on Manufacturer-Direct Business Model with the help of E-Commerce Trading
}

\author{
I. Antonitte Vinoline, W. Ritha, J. Merline Vinotha, Nivetha Martin
}

\begin{abstract}
The significance of inventory management partake in the rapid growth and development of all organizations. Inventories impacts sales and revenues, customer relations, production and operation costs etc. On the other hand, online shopping became a trendy choice among the web-users, they can buy any product either through online market places or over web stores. The main intention of this paper is to develop an inventory model based on 'Manufacturer-direct' business model with the help of e-commerce trading strategies. Also this proposed model considered the process of recycling and disposal of deteriorating items over $3 R$ approach. In order to maximize the profits and to minimize the waste generation, this model provides optimum values. Numerical examples are illustrated to validate the model.

Keywords-Inventory Model, Online shopping, E-Commerce
\end{abstract}

\section{INTRODUCTION}

In our daily life, people around the world spend their time more on the Internet for work, studies, business and entertainment. But one of the most favorable activities on the Internet is shopping. People wish to shop the products by browsing through websites or over online stores. Hence e-commerce is emerging globally. Initially, the term e-commerce implied the process of execution of commercial transactions digitally with the support of several technologies such as electronic fund transfer, online trading, digital data interchange, inventory management systems and softwares etc.

Inventory is very essential for making decisions at every step of business. Inventory openly hits the commerce on the marketplace at both countrywide and worldwide. Appropriate decisions pave a path to achieve success on business. Any source of physical stock might refer to inventory.

Later, [1] Hardy A Taha, 1999 and Sharma, J.K., 1989 were introduced some advanced topics in optimization techniques. Lerin, Rubin, Stinson, Gardner proposed the model for quantitative approaches to business management in the year 1992 .

The process of deterioration of items is frequent in our routine. According to of Wee H M in 1993, the items that become perished, dented, vanished, run-out, worthless,

Revised Version Manuscript Received on April 12, 2019.

I. Antonitte Vinoline, Department of Mathematics, Holy Cross College (Autonomous), Tiruchirapalli, Tamil Nadu, India

W. Ritha, Department of Mathematics, Holy Cross College (Autonomous), Tiruchirapalli, Tamil Nadu, India

J. Merline Vinotha, Department of Mathematics, Holy Cross College (Autonomous), Tiruchirapalli, Tamil Nadu, India

Nivetha Martin, Department of Mathematics, Arul Anandar College (Autonomous), Karumathur, Madurai, Tamil Nadu, India deflated and so on with respect to time are known as deteriorated items. Researchers exploring many types of inventory models based on deterioration. The models on perishable products were introduced by Bakker et al. [15] Karmakar and Choudhury (2010), Li et al. [10] provided a wide view on deteriorating inventory concepts. An article in the theory of perishable inventory was studied by Nahmias [8] in 1982. Pal. S, Goswami. A et al., [9](1993) developed a deterministic inventory model for deteriorating items with stock dependent demand. Recently in 2014, Ritha. W , Antonitte Vinoline. I [12], proposed an inventory model with trade credits and preservation technology for deteriorating items.

Many business organisations change their mode of selling because of various economic issues. E-Commerce plays a vital role in the world economic development. Buying through internet is a fashionable option for web-users. Nowadays, various business and management studies have focused on the internet trading strategies. Ratchford et al. [ ] told that customers love to purchase products with comparative prices with the help of web. Doolin (2005) has particularly mentioned that electronic retailing is the trade of goods and services to individual customers. But Tawfik Jelassi and Stefane Leenen (2003) had studied the impact of internet on manufacturer's sales distribution as a conceptual frame work. Ritha. W et al., [19] (2014)had intended an EPQ inventory model to advertise the business through internet to acquire international clients. Haripriya .S, Ritha. W [14] presented an e-tailing inventory model and reviewed the impacts of e-tailing in inventory management. Still the researches in e-commerce were continued because of great emergence of internet shopping world wide.

\section{A'MANUFACTURE-DIRECT' INVENTORY MODEL BASED ON E-COMMERCE STRATEGIES, RECYCLING AND DISPOSAL OF DETERIORATED ITEMS}

Among all e-business models, the manufacture direct model have more benefits To assure this, a manufacturer-direct inventory model has been developed in this paper using the ideas of basic EOQ inventory model. In addition, the models for recycling and disposal of deteriorated items were furnished. 


\subsection{Model Description}

In this modern era, the global economy was emerging with the assistance of e-commerce. Several business organizations and small companies were switching their mode of trading through Internet Manufacturers can sell their products via various e-commerce landscape using e-business models like market place models, e-tailing models with retail partners, manufacturer or factory direct models etc. Since this is a manufacturer-direct model in which the manufacturer sell their products directly to the customers without any intermediaries. Moreover, this model comprehends both $B 2 B$ and $B 2 C$ perceptions. On-line vending, Recycling and disposal of deteriorated items were conferred under two main cases,

\section{Case 1:}

In this case, the model is discussed under the concept of online vending of the products with several costs associated with e-commerce.

On-line vending requires lot of products and service displays, therefore the manufacturer can trade either through online markets or over self hosted web stores. The manufacturer can develop their own shopping site or web shop efficiently. A software is needed to setup a web store and to create a well-designed shopping site for brand recognition, grabbing the customers attention through digitalized catalog of the products. Hence software cost, website development cost are included in the model.

Cyber Security cost, cost for authentication certificate were considered to protect customer's data that includes mail id, phone number, residential address, credit and debit card details. Manufacturer can create their own payment gateway for money transactions, this leads to transaction costs and bank charges and so on.

Advertising and Marketing the shopping site through Google, face-book, twitter or any social media is an inexpensive way to promote the sales. So that advertisement cost is included. Maintenance costs includes maintenance for production, updating the software, costs involved in general services and other administrative works.

Costs for drop shipments and other modes of transportation, emission cost due to transportation were considered. Checking the quality of products is the crucial part of the production. Each and every items are constraint to screening process for checking the quality and safety of the products. Hence screening cost is required.

Packaging and preservation technology costs are inevitable for packing the parcels of food stuff with proper preservation and other parcels using Eco-friendly materials. The traditional costs of inventory such as ordering cost, purchasing cost, setup cost, holding cost were included in each cases.

\section{Case 2:}

This case deals with the deteriorated items which can be recycled and non repairable items, damaged items which are non recyclable will be assumed as wastes. Also the wastes generated during inventory operations were considered These wastes are disposed using traditional landfilling method. The costs involved in this case were deterioration cost, recycling cost, waste disposal cost and so on.

\subsection{Model Formulation}

Let us confer this model under following cases.

\section{Case 1}

This case deals with the model based on e-commerce in which the products delivered to the customers directly with no returns.

\section{Case 2}

In this case, the model is considered with deteriorated items and further categorized into two sub cases,

\section{Sub case(i)}

The deteriorated items and the products returned by the customer were recycled.

\section{Sub case 2(ii)}

The non recyclable items were disposed through the traditional landfilling method.

\subsection{Notations:}

$Q$ Ordering Quantity (in units)

$T$ Cycle Time (in days)

TC Total inventory cost

$D_{p}$ Demand Rate (in units)

$P_{r}$ Production Rate (in units)

$O_{c}$ Ordering cost per unit

$O_{p}$ Purchasing cost per unit

$O_{s}$ Setup cost per order

$O_{h}$ Stock holding cost per unit

$S_{i}$ Screening cost

$W_{d}$ Cost for developing self hosted shopping site

$S_{w}$ Software cost

$S_{S}$ Cyber security cost

$L_{c}$ Cost for authentication certificate

$A_{c}$ Advertisement cost

$R_{w}$ Ordering rate

$S_{d}$ Site demand

$L_{a}$ Charges related to legal advisor

$G_{S}$ Cost for general services

$I_{c}$ Cost for insurance coverage

$M_{c}$ Cost for subsistence of shopping site and software

$D_{c}$ Taxes and duty charges

$T_{c}$ Cost for money transactions through the payment gateway

$C_{f}$ Freight cost

$N_{s}$ Number of shipments

$E_{t}$ Emission cost due to transportation

$d_{0}$ Distance travelled

$P_{l}$ Labour wages

$P_{m}$ Material cost for packaging per parcel

$N_{m}$ Number of parcels

$n_{p}$ Number of units to preserve

$D_{a}$ Amount of deteriorated products (in units)

$d_{t}$ unit deterioration cost

$R_{n}$ Number of units to recycle over $T$

$r_{n}$ unit recycling cost 
$G_{w}$ Wastes generated during $T$ (in units)

$W_{c}$ Waste disposal cost per unit

$W_{m}$ Cost for maintaining the disposal site

$W_{l}$ Labour wages for disposing the wastes

$W_{n}$ Number of labours working in the site

$M_{e}$ Medical expenses for each labours

$Q^{*}$ Optimum order quantity

$T^{*}$ Optimal Cycle Time.

$$
\rho_{0}=1-\frac{D_{p}}{P_{r}} \geq 0
$$

$\gamma_{0}$ Average velocity

$\zeta_{0}$ unit cost for preserving the items

\section{Case 1}

The products manufactured and delivered to the customer directly. The following assumptions are used throughout this case.

\section{Assumptions}

1. Demand and Production rate is known and constant.

2. Every demand is fulfilled on the specified time.

3. Consider single manufacturer and multi-buyer for single item

4. Each product is subjected to a screening process before shipment.

5. There were no returns.

6. Both single and multiple orders are considered.

7. Customer should place the orders over the shopping site or through the web-shop owned by the manufacturer.

8. Every orders will be placed independently.

9. All bill payments were made over the payment gateway created by the manufacturer.

10. Every parcels are packed using only Eco-friendly materials.

For Manufacturer-direct inventory model, the total inventory cost comprises of website costs, Maintenance costs, screening costs, transaction charges, transportation costs, packaging and preservation costs and other traditional costs. Let the cycle time be $T=\frac{Q}{D_{p}}$.

The total cost $T C_{1}\left(Q_{1}, T_{1}\right)$ is given by,

$$
\begin{aligned}
T C_{1}\left(Q_{1}, T_{1}\right)= & \frac{1}{T_{1}}\left\{W_{d}+S_{s}+L_{c}+A_{c}\right\}+\frac{S_{d} S_{w}}{R_{w}}+ \\
& \frac{1}{T_{1}}\left\{L_{a}+G_{s}+I_{c}+M_{c}+D_{c}+S_{i}\right\}+T_{c} D_{p} T_{1}+ \\
& \frac{1}{T_{1}}\left\{N_{s} C_{f}+\frac{2 E_{t} d_{0}}{\gamma_{0}}\right\}+\frac{1}{T_{1}}\left\{P_{l} N_{m}+P_{m} N_{m}+n_{p} \zeta_{0}\right\}+ \\
& \frac{O_{c}+O_{s}+O_{p} Q_{1}}{T_{1}}+\frac{D_{p} T_{1} O_{h} \rho_{0}}{2}
\end{aligned}
$$

Now replace $T_{1}$ by $\frac{Q_{1}}{D_{p}}$ in (1), then we have

$$
\begin{aligned}
T C_{1}\left(Q_{1}, T_{1}\right)= & \frac{D_{p}}{Q_{1}}\left\{W_{d}+S_{s}+L_{c}+A_{c}+L_{a}+G_{s}+I_{c}+M_{c}+D_{c}+S_{i}\right. \\
& \left.+N_{s} C_{f}+\frac{2 E_{t} d_{0}}{\gamma_{0}}+P_{l} N_{m}+P_{m} N_{m}+n_{p} \zeta_{0}+O_{c}+O_{s}\right\} \\
& +Q_{1} T_{c}+D_{p} O_{p}+\frac{Q_{1} O_{h} \rho_{0}}{2}
\end{aligned}
$$

Using method of differential calculus we obtain the optimal values $Q_{1}^{*}$ and $T_{1}^{*}$ by differentiating (2) and (1) respectively. Then the first derivative is equated to zero.

$$
T C_{1}\left(Q_{1}, T_{1}\right) Q_{1}=-\frac{D_{p} Y}{Q_{1}^{2}}+T_{c}+\frac{O_{h} \rho_{0}}{2}
$$

Where,

$$
\begin{array}{r}
Y=W_{d}+S_{s}+L_{c}+A_{c}+L_{a}+G_{s}+I_{c}+M_{c}+D_{c}+S_{i} \\
+N_{s} C_{f}+\frac{2 E_{t} d_{0}}{\gamma_{0}}+P_{l} N_{m}+P_{m} N_{m}+n_{p} \zeta_{0}+O_{c}+O_{s}
\end{array}
$$

Now

$$
\begin{aligned}
& T C_{1}\left(Q_{1}, T_{1}\right) Q_{1}=0 \\
& \frac{D_{p} Y}{Q_{1}^{2}}=T_{c}+\frac{O_{h} \rho_{0}}{2} \\
& Q_{1}^{2}=\frac{D_{p} Y}{T_{c}+\frac{O_{h} \rho_{0}}{2}}
\end{aligned}
$$

$Q_{1}=Q_{1}^{*}=\sqrt{\frac{D_{p} Y}{T_{c}+\frac{O_{h} \rho_{0}}{2}}}$

The above equation(4) is the required optimal order quantity for case 1.Similarly, by differentiating (1) with respect to $T_{1}$ and using (3), we have

$$
T C_{1}\left(Q_{1}, T_{1}\right) T_{1}=-\frac{Y+O_{p} Q_{1}}{T_{1}^{2}}+D_{p}\left\{T_{c}+\frac{O_{h} \rho_{0}}{2}\right\}
$$

Then

$$
\begin{aligned}
& T C_{1}\left(Q_{1}, T_{1}\right) T_{1}=0 \\
& \frac{Y+O_{p} Q_{1}}{T_{1}^{2}}=D_{p}\left\{T_{c}+\frac{O_{h} \rho_{0}}{2}\right\} \\
& T_{1}^{2}=\frac{Y+O_{p} Q_{1}}{D_{p}\left\{T_{c}+\frac{O_{h} \rho_{0}}{2}\right\}}
\end{aligned}
$$

$$
T_{1}=T_{1}^{*}=\sqrt{\frac{Y+O_{p} Q_{1}}{D_{p}\left\{T_{c}+\frac{O_{h} \rho_{0}}{2}\right\}}}
$$

The above equation (5) is the required optimal cycle time for case 1.

\section{Case 2}

In this case, the model is considered with deteriorated items and further categorized into two sub cases,

\section{Sub case(i)}

The deteriorated items and the products returned by the customer were recycled.

\section{Assumptions}

The assumptions for this case are listed below.

1. Detrioration rate is known and constant

2. Items like food stuff, dress materials and other organic wastes are recycled.

3. Recycled products were reused for further manufacturing purposes.

4. The total deterioration cost is given by $\frac{D_{a} d_{t}}{T_{2}}$

The total cosist of screening cost, deterioration cost, recycling cost and other tradition costs.

Published By: 
The total cost $T C_{2}\left(Q_{2}, T_{2}\right)$ is given by,

$$
\begin{aligned}
T C_{2}\left(Q_{2}, T_{2}\right)= & \frac{S_{i}+D_{a} d_{t}+R_{n} r_{n}}{T_{2}}+\frac{O_{c}+O_{s}}{T_{2}} \\
& +\frac{O_{p} Q_{2}}{T_{2}}+\frac{D_{p} T_{2} O_{h} \rho_{0}}{2}
\end{aligned}
$$

Now replace $T_{2}$ by $\frac{Q_{2}}{D_{p}}$ in (6), then we have

$$
\begin{aligned}
T C_{2}\left(Q_{2}, T_{2}\right)= & \frac{D_{p}}{Q_{2}}\left\{S_{i}+D_{a} d_{t}+R_{n} r_{n}+O_{c}+O_{s}\right\} \\
& +D_{p} O_{p}+\frac{Q_{2} O_{h} \rho_{0}}{2}
\end{aligned}
$$

Let us consider

$Z=S_{i}+D_{a} d_{t}+R_{n} r_{n}+O_{c}+O_{s}$

Use (8) and differentiate (7) with respect to $Q_{2}$ we have,

$$
\begin{aligned}
& T C_{2}\left(Q_{2}, T_{2}\right) Q_{2}=-\frac{D_{p} Z}{Q_{2}^{2}}+\frac{O_{h} \rho_{0}}{2} \\
& T C_{2}\left(Q_{2}, T_{2}\right) Q_{2}=0 \\
& \frac{D_{p} Z}{Q_{2}^{2}}=\frac{O_{h} \rho_{0}}{2} \\
& Q_{2}^{2}=\frac{2 D_{p} Z}{O_{h} \rho_{0}} \\
& Q_{2}=Q_{2}^{*}=\sqrt{\frac{2 D_{p} Z}{O_{h} \rho_{0}}}
\end{aligned}
$$

The above equation( $(9)$ is the required optimal order quantity for this sub case.

In order to obtain optimal cycle time $T_{2}^{*}$, differentiate (6)with respect to $T_{2}$ and using (8), we have

$$
T C_{2}\left(Q_{2}, T_{2}\right) T_{2}=-\frac{\left(Z+O_{p} Q_{2}\right)}{T_{2}^{2}}+D_{p} \frac{O_{h} \rho_{0}}{2}
$$

Then

$$
\begin{aligned}
& T C_{2}\left(Q_{2}, T_{2}\right) T_{2}=0 \\
& \begin{array}{l}
\frac{Z+O_{p} Q_{2}}{T_{2}^{2}}=D_{p} \frac{O_{h} \rho_{0}}{2} \\
T_{2}^{2}=\frac{2\left(Z+O_{p} Q_{2}\right)}{D_{p} O_{h} \rho_{0}}
\end{array} T_{2}=T_{2}^{*}=\sqrt{\frac{2\left(Z+O_{p} Q_{2}\right)}{D_{p} O_{h} \rho_{0}}}
\end{aligned}
$$

The above equation (10) is the required optimal cycle time for this sub case.

Let us formulate sub-case 2 ,

\section{Sub case(ii)}

The non recyclable items were disposed through the traditional landfilling method.

\section{Assumptions}

The assumptions for this case are listed below.

1. Detrioration rate is known and constant

2. Wastes generated during inventory operations are also considered.

3. Land filling method is used to dispose the wastes.

4. The total deterioration cost is given by $\frac{D_{a} d_{t}}{T_{3}}$

5. Transportation is needed to shift the wastes to the disposal site.

6. Emission cost is included due to transportation.

The total comprises of screening cost, deterioration cost, waste disposal cost, transportation cost, emission cost and other tradition costs.

The total cost $T C_{3}\left(Q_{3}, T_{3}\right)$ is given by,

$$
\begin{aligned}
T C_{3}\left(Q_{3}, T_{3}\right)= & \frac{S_{i}+D_{a} d_{t}+O_{c}+O_{s}}{T_{3}}+\frac{C_{f}+\frac{2 E_{t} d_{0}}{\gamma_{0}}}{T_{3}} \\
& +\frac{G_{w} W_{c}+W_{m}+W_{n} W_{l}+W_{n} M_{e}}{T_{3}}+\frac{O_{p} Q_{3}}{T_{3}} \\
& +\frac{D_{p} T_{3} O_{h} \rho_{0}}{2}
\end{aligned}
$$

Let

$$
\begin{aligned}
W= & S_{i}+D_{a} d_{t}+O_{c}+O_{s}+C_{f}+\frac{2 E_{t} d_{0}}{\gamma_{0}} \\
& +G_{w} W_{c}+W_{m}+W_{n} W_{l}+W_{n} M_{e}
\end{aligned}
$$

Replace $T_{3}=\frac{Q_{3}}{D_{p}}$ in (11) and differentiate it with respect to $Q_{3}$ gives,

$$
T C_{3}\left(Q_{3}, T_{3}\right) Q_{3}=-\frac{D_{p} W}{Q_{3}^{2}}+\frac{O_{h} \rho_{0}}{2}
$$

Now

$$
\begin{aligned}
& T C_{3}\left(Q_{3}, T_{3}\right) Q_{3}=0 \\
& \frac{D_{p} W}{Q_{3}^{2}}=\frac{O_{h} \rho_{0}}{2} \\
& Q_{3}^{2}=\frac{2 D_{p} W}{O_{h} \rho_{0}}
\end{aligned}
$$

$Q_{3}=Q_{3}^{*}=\sqrt{\frac{2 D_{p} W}{O_{h} \rho_{0}}}$

The above equation(13) is the required optimal order quantity for this sub case.In order to obtain optimal cycle time $T_{3}^{*}$, differentiate (11) again with respect to $T_{3}$ and using (12), we have

$$
T C_{3}\left(Q_{3}, T_{3}\right) T_{3}=-\frac{\left(W+O_{p} Q_{3}\right)}{T_{3}^{2}}+D_{p} \frac{O_{h} \rho_{0}}{2}
$$

Then

$$
\begin{aligned}
& T C_{3}\left(Q_{3}, T_{3}\right) T_{3}=0 \\
& \frac{W+O_{p} Q_{3}}{T_{3}^{2}}=D_{p} \frac{O_{h} \rho_{0}}{2} \\
& T_{3}^{2}=\frac{2\left(W+O_{p} Q_{3}\right)}{D_{p} O_{h} \rho_{0}} \\
& T_{3}=T_{3}^{*}=\sqrt{\frac{2\left(W+O_{p} Q_{3}\right)}{D_{p} O_{h} \rho_{0}}}
\end{aligned}
$$

The above equation(14) gives the optimal cycle time for this sub case. Hence the optimal values of case 2 are found out from the above sub-cases. To validate this model, several numerical examples were discussed in next chapter. 


\section{NUMERICAL EXAMPLE \& RESULTS}

\section{Example 1:}

\begin{tabular}{|c|c|c|c|c|}
\hline $\begin{array}{l}D_{p} \\
=200\end{array}$ & $P_{r}=400$ & $O_{c}=.05$ & $\begin{array}{l}O_{p} \\
=0.08\end{array}$ & $O_{s}=0.1$ \\
\hline $\begin{array}{l}O_{h} \\
=0.05\end{array}$ & $S_{i}=0.07$ & $W_{d}=.40$ & $\begin{array}{l}S_{w} \\
=1.40\end{array}$ & $\begin{array}{l}S_{s} \\
=0.25\end{array}$ \\
\hline $\begin{array}{l}L_{c} \\
=0.28\end{array}$ & $A_{c}=0.3$ & $R_{w}=75$ & $S_{d}=100$ & $L_{a}=0.4$ \\
\hline $\begin{array}{l}G_{s} \\
=0.30\end{array}$ & $I_{c}=0.7$ & $M_{c}=0.6$ & $\begin{array}{l}D_{c} \\
=0.36\end{array}$ & $\begin{array}{l}T_{c} \\
=0.06\end{array}$ \\
\hline $\begin{array}{l}C_{f} \\
=0.05\end{array}$ & $N_{s}=10$ & $\begin{array}{l}E_{t} \\
=0.03\end{array}$ & $d_{0}=250$ & $\begin{array}{l}P_{l} \\
=0.008\end{array}$ \\
\hline $\begin{array}{l}P_{m} \\
=0.01\end{array}$ & $N_{m}=$ & $n_{p}=20$ & $\begin{array}{l}D_{a} \\
=100\end{array}$ & $\begin{array}{l}d_{t} \\
=0.01\end{array}$ \\
\hline$=60$ & $r_{n}=0.02$ & $G_{w}=40$ & $\begin{array}{l}W_{c} \\
=0.004\end{array}$ & $\begin{array}{l}W_{m} \\
=0.07\end{array}$ \\
\hline & W & $\begin{array}{l}M_{e} \\
=0.05\end{array}$ & $\gamma_{0}=180$ & $\begin{array}{l}\zeta_{0} \\
=0.007\end{array}$ \\
\hline
\end{tabular}

Solution:

For Case 1, Using the given data in equation(3), we have, $Y=5.2533$

To find $Q_{1}^{*}, T_{1}^{*}$ we can use the expression (4,5),Then

$$
\begin{aligned}
& Q_{1}^{*}=\sqrt{\frac{200 \times 5.2533}{0.06+0.0125}}=120.3822=120 \text { units } \\
& T_{1}^{*}=\sqrt{\frac{14.8839}{14.5}}=1.0132=1 \text { day }
\end{aligned}
$$
have

The total cost $T C_{1}\left(Q_{1}, T_{1}\right)$ is given by the equation(1),we

$$
T C_{1}\left(Q_{1}, T_{1}\right)=14.69+12.1584+2.5330+1.8667=31.25 \mathrm{USD}
$$

For case 2, we have to find optimal values for two sub-cases.

For sub-case 1, Substituting the relevant parametric values in equation(8), we get $Z=2.42$.

To find $Q_{2}^{*}, T_{2}^{*}$ we can use the expression $(9,10)$, Then

$$
\begin{aligned}
& Q_{2}^{*}=\sqrt{\frac{2 \times 200 \times 2.42}{0.025}}=196.7740=197 \text { units } \\
& T_{2}^{*}=\sqrt{\frac{36.3238}{5}}=2.6953=3 \text { days }
\end{aligned}
$$

The total cost $T C_{2}\left(Q_{2}, T_{2}\right)$ is given by the equation(6),we have

$$
T C_{2}\left(Q_{2}, T_{2}\right)=6.7384+6.7383=13.48 \mathrm{USD}
$$

For sub-case 2, For sub-case 1, Substituting the relevant parametric values in equation(12), we get $W=2.1333$.

To find $Q_{3}^{*}, T_{3}^{*}$ we can use the expression $(13,14)$,Then

$$
\begin{aligned}
& Q_{3}^{*}=\sqrt{\frac{2 \times 200 \times 2.1333}{0.025}}=184.7506=185 \text { units } \\
& T_{3}^{*}=\sqrt{\frac{33.8268}{5}}=2.6010=3 \text { days }
\end{aligned}
$$

The total cost $T C_{3}\left(Q_{3}, T_{3}\right)$ is given by the equation(11),we have

$$
T C_{3}\left(Q_{3}, T_{3}\right)=6.5026+6.5025=12.56 \mathrm{USD}
$$

Hence the optimal values of for case 1,2 were obtained. Example 2:

$$
\begin{aligned}
& \begin{array}{lllll}
D_{p} & P_{r}=400 & O_{c}=.05 & O_{p} & O_{s}=0.1
\end{array} \\
& =250 \quad=0.08 \\
& \begin{array}{lllll}
O_{h} & S_{i}=0.07 & W_{d}=.40 & S_{w} & S_{s}
\end{array} \\
& =0.05 \quad=1.40=0.25 \\
& L_{c} \quad A_{c}=0.3 \quad R_{w}=50 \quad S_{d}=80 \quad L_{a}=0.4 \\
& \begin{array}{lllll}
=0.28 & & & & \\
G_{s} & I_{c}=0.7 & M_{c}=0.6 & D_{c} & T_{c}
\end{array} \\
& =0.30 \quad=0.36=0.06 \\
& \begin{array}{lllll}
C_{f} & N_{s}=20 & E_{t} & d_{0} & P_{l}
\end{array} \\
& \begin{array}{lll}
=0.05 & =0.03=250=0.008
\end{array} \\
& P_{m} \quad N_{m}=45 \quad n_{p}=30 \quad D_{a}=60 \quad d_{t} \\
& =0.01 \quad=0.01 \\
& \begin{array}{lllll}
R_{n} & r_{n} & G_{w}=20 & W_{c} & W_{m}
\end{array} \\
& \begin{array}{llll}
=40 & =0.02 & =0.004 & =0.07
\end{array} \\
& \begin{array}{lllll}
W_{l} & W_{n}=5 & M_{e} & \gamma_{0}=180 \quad \zeta_{0}
\end{array} \\
& \begin{array}{lll}
=0.06 & =0.05 & =0.007
\end{array}
\end{aligned}
$$

\section{Solution:}

For Case 1, Using the given data in equation(3), we have, $Y=5.1933$

To find $Q_{1}^{*}, T_{1}^{*}$ we can use the expression $(4,5)$, Then

$$
\begin{aligned}
& Q_{1}^{*}=\sqrt{\frac{250 \times 5.1933}{0.0694}}=145.95=146 \text { units } \\
& T_{1}^{*}=\sqrt{\frac{17.8839}{17.35}}=1.0069=1 \text { day }
\end{aligned}
$$

The total cost $T C_{1}\left(Q_{1}, T_{1}\right)$ is given by the equation(1),we have

$$
T C_{1}\left(Q_{1}, T_{1}\right)=17.4688+15.1035+2.3362+2.24=37.18 \mathrm{USD}
$$

For case 2, we have to find optimal values for two sub-cases.

For sub-case 1, Substituting the relevant parametric values in equation(8), we get $Z=1.62$.

To find $Q_{2}^{*}, T_{2}^{*}$ we can use the expression $(9,10)$, Then 


$$
\begin{aligned}
& Q_{2}^{*}=\sqrt{\frac{2 \times 250 \times 1.62}{0.0188}}=207.57=208 \text { units } \\
& T_{2}^{*}=\sqrt{\frac{36.4512}{4.7}}=2.7849=3 \text { days }
\end{aligned}
$$

The total cost $T C_{2}\left(Q_{2}, T_{2}\right)$ is given by the equation(6),we have

$$
T C_{2}\left(Q_{2}, T_{2}\right)=6.5445+6.5445=13.09 \mathrm{USD}
$$

For sub-case 2, For sub-case 1, Substituting the relevant parametric values in equation(12), we get $W=1.6533$.

To find $Q_{3}^{*}, T_{3}^{*}$ we can use the expression $(13,14)$, Then

$$
\begin{aligned}
& Q_{3}^{*}=\sqrt{\frac{2 \times 250 \times 1.6533}{0.0188}}=209.70=210 \text { units } \\
& T_{3}^{*}=\sqrt{\frac{33.8574}{4.7}}=2.8004=3 \text { days }
\end{aligned}
$$

The total cost $T C_{3}\left(Q_{3}, T_{3}\right)$ is given by the equation(11), we have

$$
T C_{3}\left(Q_{3}, T_{3}\right)=6.5807+6.5809=13.16 \mathrm{USD}
$$

Hence the optimal values of for case 1, 2 were obtained.

\section{CONCLUSION}

Nowadays, the world is digitalised and the e-commerce is booming. Notably, the online shopping is a contemporary option, that was favoured by many internet users throughout the world. E-commerce reinforces the flexibility of the business. The 'manufacturer-direct business model under e-commerce landscape becomes cost effective inventory model with the assistance of proper inventory management and e-trading strategies.

According to several environmental regulations, the $3 R$ is an authentic one, which is needed for curtailing the effect of deterioration. Also this approach is alluring for minimization of wastes. So that, the deteriorated items like food stuff, damage cloths and other organic wastes will be recycled and reused for the future production. Some of the recycled items are considered to be new ones. This $3 R$ approach will reduce the utilization of new raw materials and have control in the carbon foot print while using land filling method for waste disposal. Hence the model is eco-friendly. In Future, the model can be extend further with consideration of shortages, trade credits etc.

\section{REFERENCES}

1. Taha. AH, Operations Research Introduction, Macmillan Publication Company,New York. 1971.

2. Zipkin, P.H., Foundations of Inventory Management, McGraw Hill, New York, 2000.

3. Wilson R.H., A scientific routine for stock control. Harvard Business Review, 1934, 13, 116-128.1848

4. Mahadevan S., Factory Organisation and Management Control, Academic Publishers : Calcutta 1972 : P 93.

5. Fred Hanssman., A survey of Inventory theory from operations research : Wiley and Sons Inc. : Ed 1961 : P 65.

6. Burwell T.H., Dave D.S., Fitzpatrick K.E., Roy M.R., Economic lot size model for price-dependent demand under quantity and freight discounts, International Journal of Production Economics, 1997, 48(2), 141-155.

7. Nahmias S., Perishable inventory theory a review. Operations Research, 1982, 30, 680-708.

8. Pal, S., Goswami.A and Chaudhari, K.S., A deterministic inventory model for deteriorating items with stock dependent demand rate, International Journal of Production Economics, 1993, 32, 291-299.

9. You, S.P., Inventory policy for products with price and time-dependent demands, Journal of the Operational Research Society, 2005, 56, 870-873.

10. Ruxian Li., A review on Deteriorating inventory study, Journal of Service Science and Management, 2010, 3:117-129

11. Ritha.W and Antonitte Vinoline.I,Quality improved integrated inventory model with trade credit and preservation Technology, Elixir Appl. Math. 72 (2014) 25764-25777

12. W. Ritha*, S. Haripriya, Green inventory model with vendor-buyer environmental collabration to achieve sustainability,Internation Journal of sciences and research technology, DOI:10.5281/zenodo.569942.

13. S. Haripriya et al.,An Eco-friendly inventory model for food items to reduce quality loss with profit maximization, International Journal of Computer Science and Mobile Computing, Vol.5 Issue.7, July-2016, pg. 489-497

14. Ritha. W et al., An impact of E-tailing in inventory management, International Journal of Latest Research in Engineering and Technology (IJLRET) ISSN: 2454-5031 Volume 02 - Issue 08, August 2016, PP. 40-46

15. Bakker,M., Riezebos,J and Teunter,R.H.(2012), Review of inventory systems with deterioration since 2011, European Journal of Operational Research, Vol. 221 No. 2, pp. 275-284.

16. Ben-Daya, M., Darwish, M. and Ertogral, K. (2008), The joint economic lot sizing problem: review and extensions, European Journal of Operational Research, Vol. 185 No. 2, pp. 726-742.

17. Bonney, M. and Jaber, M.Y. (2012), Environmentally responsible inventory models: non-classical models for non-classical era, International Journal of Production Economics, Vol. 133 No. 1, pp. 43- 53.

18. Bouchery, Y., Ghaffari, A., Jemai, Z. and Dallery, Y. (2012), Including sustainability criteria in inventory models, European Journal of Operational Research, Vol. 222 No. 2, pp. 229-240.

19. W.Ritha, Nivetha Martin. (2014, March 14). Economic Production Inventory model with the associated costs of internet advertising to acquire customers residing worldwide, International Journal Of Computers and Technology, 12(9), 3921-3926.

20. Ratchford, B.T., Talukdar ,D.and Lee, M.S. (2001): A model of consumer choice of the Internet as an information source, International Journal of Electronic commerce, vol. 5, no. 3, pp. $7-21$ 